\title{
Legislação e ferramentas de gestão no controle de qualidade da matéria-prima na fabricação de rações
}

\section{Legislation and management tools in raw material quality control in feed manufacturing}

\section{Legislación y herramientas de gestión en el control de calidad de la materia prima en la fabricación de raciones}

\author{
Melo B.S. de Araújo ${ }^{1}$ Zootec; Amaral A. das Graças ${ }^{2}$ Ph.D; Pereira K. Augusto ${ }^{3}$ M.Sc; \\ Rocha L.R. de Oliveira ${ }^{3}$ M.Sc; Taveira R. Zaiden ${ }^{1}$ Ph.D.
}

${ }^{1}$ Universidade Estadual de Goiás (UEG), Câmpus São Luís de Montes Belos. Goiás. Brasil.

2Universidade Federal dos Vales do Jequitinhonha e Mucuri (UFVJM).

Diamantina. Minas Gerais. Brasil.

3Universidade Estadual de Goiás (UEG), Cãmpus Anápolis de Ciências Exatas e Tecnológicas Henrique Santillo. Anápolis, Goiás. Brasil.

KEYWORDS:

Critical points; hazard analysis; standard operating; procedure.

\section{ABSTRACT}

The objective of this review was to gather theoretical knowledge about legislation and management tools in the quality control of raw material in the production of feed for production animals, describing the regulation and inspection in the processes involved, highlighting the importance that such procedures in the final product result. Thus, it is evident that the quality control of the raw material is essential in order to guarantee the safety of a reliable final product, which meets the market and consequently the animal requirements, which is close to the specifications or standards established for which it was created and that complies with current legislation and inspections of federal agencies related to the sector. It is essential to use such management tools in the quality and safety of food offered to production animals. In which, Good Manufacturing Practices and Standard Operating Procedures are essential prerequisites for the implementation of Hazard Analysis and Critical Control Points.

\section{RESUMO}

Objetivou-se com a presente revisão, reunir aporte teórico, acerca da legislação e ferramentas de gestão no controle de qualidade da matériaprima na fabricação de ração para animais de produção, descrevendo a regulamentação e fiscalização nos processos envolvidos, ressaltando a importância que tais procedimentos exercem no resultado final do produto. Assim, evidencia-se que o controle de qualidade da matériaprima é essencial a fim de assegurar a garantia da inocuidade de um produto final de confiança, que atenda às exigências do mercado e consequentemente dos animais, que se aproxime ao máximo das especificações ou padrões estabelecidos para o qual fora criado e que atenda à legislação vigente e às inspeções dos órgãos federais ligados ao setor. Fazendo-se imprescindível o uso de tais ferramentas de gestão na qualidade e segurança dos alimentos oferecidos aos animais de produção. Em que, as Boas Práticas de Fabricação e o Procedimento Operacional Padrão são pré-requisitos essenciais à implantação da Análise de Perigo e Pontos Críticos de Controle. 
PALABRAS CLAVE:

Análisis de peligro; puntos críticos; procedimiento operativo; estándar

\section{RESUMEN}

La presente revisión tuvo como objetivo, reunir el aporte teórico, acerca de la legislación y herramientas de gestión en el control de calidad de la materia prima en la fabricación de raciones para animales de producción, describiendo la reglamentación y fiscalización en los procesos involucrados, resaltando la importancia que tales procedimientos ejercen en el resultado final del producto. Así, se evidencia que el control de calidad de la materia prima es esencial para asegurar la inocuidad de un producto final de confianza, que atienda a las exigencias del mercado y consecuentemente de los animales, que se aproxime al máximo de las especificaciones o patrones establecidos para el cual fue creado y que atienda a la legislación vigente y a las inspecciones de los órganos federales ligados al sector. Se hace imprescindible el uso de tales herramientas de gestión en la calidad y seguridad de los alimentos ofrecidos a los animales de producción. En que, las Buenas Prácticas de Fabricación y el Procedimiento Operativo Estándar son prerrequisitos esenciales para la implantación del Análisis de Peligros y Puntos Críticos de Control.

\section{INTRODUÇÃO}

Diante do crescimento ascendente na produção de ração destinada a nutrição animal, houve aumento produtivo de $19 \%$ nos últimos cinco anos o setor atingiu a marca inédita de 1 bilhão de toneladas produzidas, o Brasil manteve a liderança na produção de ração da América Latina, segundo levantamento da ALLTECH GLOBAL FEED SURVEY (2017).

Os alimentos destinados a alimentação dos animais, apresentam liderança na indústria global de alimentos. As rações são o componente de maior importância para garantir fontes proteicas aos animais de maneira segura, abundante e acessíveis (IFIF 2014). Tal magnitude está atrelada ao fato do Brasil possuir 225 milhões de bovinos e destes, 5 milhões foram confinados no ano de 2016, com a necessidade produtiva de consumo de rações durante toda a cadeia de produção da carne bovina. Já para o sistema avícola e suinícola em sua totalidade é dependente do fornecimento de rações tornando-se de grande representatividade para o setor industrial (ABIEC, 2017 e WEDEKIN et al., 2017).

Para o setor industrial, faz-se necessário diferenciar seus produtos de seus competidores, almejando a satisfação do cliente. A busca pela qualidade e produtividade passa por diversas questões, como políticas de gestão da qualidade, análise do melhor sistema de produção, treinamento, manutenção da produção, escolha apropriada de fornecedores, além de outros fatores estratégicos como ferramentas de gestão dos quais são imprescindíveis a fim de tais segmentos se manterem competitivos no mercado e conseguir galgar outros mercados, como por exemplo o externo (CORADI et al., 2009).

Pode-se ressaltar a importância do estudo referente a dinâmica diária de uma fábrica de rações, sendo imprescindível a observação, avaliação e bom senso na tomada de decisões para que a ação correspondente seja eficiente e eficaz. Pois, a indústria de alimentos destinados a nutrição animal é um setor tão importante quanto qualquer outro dentro da área de produção animal, deste modo, este segmento não pode ficar à mercê de procedimentos inadequados. Com visão no futuro e ações concretas no presente os profissionais precisam nortear seu trabalho a fim de garantir qualidade do produto final e melhores resultados técnicos e econômicos (COUTO, 2008).

Ao passo que uma empresa produtora de rações deve possuir um eficiente controle de qualidade dos ingredientes disponíveis e que garantam a qualidade da ração 
Melo et al - Legislação e ferramentas de gestão no controle de qualidade da matéria-prima

produzida. Com isto, são necessários constantes monitoramentos na qualidade dos ingredientes que compõem a ração e no processo de produção, com intuito de identificar e solucionar os problemas evitando perdas ou falhas. Fazendo-se necessário gerenciar com eficácia cada etapa do processo produtivo (ALVES e BIAGI, 2005).

Portanto, objetivou-se com a presente revisão de literatura, reunir aporte teórico, acerca da legislação e ferramentas de gestão no controle de qualidade da matéria-prima na fabricação de ração para animais de produção, descrevendo a regulamentação e fiscalização nos processos envolvidos, ressaltando a importância que tais procedimentos exercem no resultado fina do produto acabado.

\section{Legislação no Controle de Qualidade da Matéria-Prima}

Aliando a foto da perspectiva referente ao crescimento da produção e na exportação de ração para a próxima década, fazse necessário intensificar de maneira expressiva os índices zootécnicos no campo intensificando a fiscalização do setor de produtos destinados à alimentação animal. Todo estabelecimento fabricante de alimentos para animais deve ser registrado no Ministério da Agricultura, Pecuária e Abastecimento (MAPA) e observar as legislaçoes vigentes. A fiscalização destes estabelecimentos têm como proposito garantir adequadas condições higienicosanitária nos processos de fabricação, bem como a conformidade e inocuidade dos produtos disponibilizados no mercado, primando pela segurança alimentar e a rastreabilidade dos produtos importados e exportados (MAPA, 2014).

No Brasil, a alimentação animal é regulamentada pela Lei ordinária no 6.198 , de 26 de dezembro de 1974, que dispõe sobre a inspeção e fiscalização obrigatórias dos produtos destinados a alimentação animal. Em conformidade com este decreto no 6.296, de 11 de dezembro de 2007, que aprovou a lei no 6.198, nos termos da Lei os produtos destinados à alimentação animal somente poderão ser produzidos, fabricados, fracionados, e embalados, importados, exportados, armazenados, comercializados ou utilizados em conformidade com tal decreto (MAPA, 2014).

Do mesmo modo foi reiterada pela Lei 11.105 de 2005 (Lei de Biossegurança) artigo 40 qestabelece a rotulagem de rações produzidas com matéria-prima de origem transgênica, quando há presença acima de $1 \%$ em sua composição. Uma vez que essa informação deve acompanhar o ingrediente em todas as etapas da cadeia produtiva (BRANQUINHO et al., 2015).

Especificamente no que se refere à indústria de alimentos para animais, o MAPA estabeleceu através da instrução normativa n$^{\circ} 4$, de 23 de fevereiro de 2007, o regulamento técnico sobre as condições higiênicas sanitárias e de Boas práticas de fabricação (BPF) para estabelecimentos fabricantes de produtos destinados à alimentação animal (BRASIL, 2007).

A instrução normativa (IN) $n^{0} 4$ se divide em dois anexos. O anexo I é o regulamento técnico sobre as condições higiênicosanitárias e de BPF para estabelecimentos fabricantes de produtos destinados a alimentação animal e o anexo II, é o check list, utilizado para pontuar os estabelecimentos. Esta instrução tem como objetivo, definir os procedimentos básicos de higiene e de BPF para alimentos fabricados e industrializados para o consumo dos animais, desse modo, se aplica a todo estabelecimento fabricante ou fracionador de produtos para animais com o intuito de elaborar e implementar o manual de BPF (MASCARENHAS, 2012).

No que se refere a obtenção de produtos de qualidade no processo de fabricação de ração, ressaltasse a atenção necessária desde o projeto da fábrica, envolvendo a sua construção, a seleção e instalação dos seus equipamentos, a rígida escolha dos fornecedores de ingredientes, o estabelecimento das fórmulas das rações, a supervisão da qualidade dos ingredientes alimentícios, a pesagem 
correta, armazenagem, características da moagem, a pré-mistura de concentrados e suplementos vitamínicos, a mistura dos alimentos, supervisão da ração pronta, a manutenção e limpeza dos equipamentos da fábrica e, por fim, a higienização geral da fábrica (CORADI et al., 2009).

De acordo com COUTO (2008), o conceito de qualidade é bastante amplo, no entanto o programa de controle de qualidade na indústria de rações pode ser entendido como o conjunto de ações direcionadas no propósito de assegurar que o produto final se aproxime ao máximo das especificações ou padrões estabelecidos.

Um levantamento sobre a contaminação por Salmonella spp., foi realizado na Espanha no ano de 2011, em relação aos principais ingredientes disponiveis para nutrição animal. Já no ano de 2012 o mesmo estudo foi realizada na União Europeia. Puderam verificar que a contaminação estava presente nos diferente ingredientes e de forma variada (Tabela 1 e 2) (SILVEIRA, 2014), o que denota falhas na implantação e uso das BPF, corroborando com o relatado por TORRES et al. (2011) e SORIA et al. (2013).

Tabela 1. Ocorrência de contaminação por Salmonella spp. em amostras de diferentes ingredientes na Espanha em 2001.

\begin{tabular}{lcc}
\hline \multicolumn{1}{c}{ Ingrediente } & $\begin{array}{c}\text { Salmonella spp. } \\
(\%)\end{array}$ & $\begin{array}{c}\text { No de } \\
\text { Amostras }\end{array}$ \\
\hline Farelo de trigo & 28,3 & 85 \\
Cevada & 16,3 & 123 \\
Milho & 1,1 & 298 \\
Farelo de soja & 10,8 & 464 \\
Farelo de girassol & 10,9 & 70 \\
Farinha de carne & 17,4 & 109 \\
Farinha de peixe & 13,6 & 61 \\
\hline
\end{tabular}

Fonte: Adaptado de LONGO; SILVA e LANZARIM (2010).

Diante das referidas ponderações o controle de qualidade nas indústrias fabricantes de ração se faz muito importante e necessário, tanto sob o aspecto econômico como em relação à saúde dos animais que o consomem (CHAVES, 1994).
Tabela 2. Ocorrência de contaminação por Salmonella spp. em amostras de ingredientes coletadas na União Européia em 2002.

\begin{tabular}{lcc}
\hline Ingrediente & $\begin{array}{c}\text { Salmonella } \\
\text { spp. (\%) }\end{array}$ & $\begin{array}{c}\text { No de } \\
\text { Amostras }\end{array}$ \\
\hline Milho & 2,43 & 1315 \\
Farelo de Soja & 2,78 & 5937 \\
Oleaginosas & 5,95 & 9305 \\
Farinha de Carne & 1,48 & 7102 \\
Farinha de Peixe & 3,13 & 6670 \\
Proteínas Animais & 0,84 & 42000 \\
Proteínas Vegetais & 2,30 & 77481 \\
\hline
\end{tabular}

Fonte: Adaptado de LONGO; SILVA e LANZARIM (2010).

Desse modo, os responsáveis pela qualidade dos materiais na produção do produto final (ração) precisam ter treinamento e conhecimento suficiente sobre as boas práticas de fabricação e a legislação estabelecida, para identificar os perigos relacionados à inocuidade e estabelecer os processos de controle (MAPA, 2007).

Portanto, para se ter qualidade no produto final torna-se irrefutável a necessidade de inspeções de qualidade dos ingredientes que chegam à fábrica e nos produtos acabados de forma cotidiana, os quais podem conter as provas laboratoriais de composição bromatológica (MORAES, 1997).

ROSÁRIO (2004) utilizou da argumentação que a evolução do controle da qualidade possibilite não só que a empresa reduza a frequência de erros, como também aumente o rendimento, a capacidade, o desempenho da produção e a maximização de serviços e produtos em conformidade com as características para as quais foram criadas. Praticar um bom controle de qualidade visa desenvolver, projetar, produzir e comercializar um produto de qualidade, que atenda as exigências do consumidor.

Fazendo necessário a implementação eficaz das de ferramentas de gestão como Boas Práticas de Fabricação (BPF), Procedimento operacional padrão (POP) e dos princípios do sistema de Análise de Perigos e Pontos 
Melo et al - Legislação e ferramentas de gestão no controle de qualidade da matéria-prima

Críticos de Controle (APPCC) em toda a cadeia produtiva é uma medida importante para manter o controle e assegurar a qualidade dos produtos alimentícios. Nesta implementação, o uso das tecnologias e de profissionais qualificados são os principais determinantes de resultados satisfatórios (OLIVEIRA et al., 2012).

\section{Ferramentas de Gestão no Controle de Qualidade da Matéria-Prima}

Boas práticas de fabricação (BPF). Criado pelo Food and Drug Administration (FDA), no ano de 1969, as Boas Práticas de Fabricação (BPF) (GMP - "Good Manufaturing Practices"), conceitualmente, são um conjunto de práticas recomendadas no manuseio dos alimentos, tendo em vista a obtenção de alimentos seguro (REZENDE, 2003).

Por conseguinte, as BPF são um conjunto de normas que definem a infraestrutura e os procedimentos higiênicos, sanitários e operacionais aplicados em todo o fluxo de produção, desde a obtenção dos ingredientes e matérias-primas até a distribuição do produto final, com o objetivo de garantir a qualidade, conformidade e segurança dos produtos destinados a alimentação animal (MAPA, 2007).

No entanto as BPF não envolvem somente o monitoramento do processo de fabricação dos produtos, mas abrangem, dentre outros procedimentos, a participação das pessoas, o processo de produção, as condições de uso dos equipamentos, a matéria-prima, as embalagens e os rótulos, a manutenção, a segurança e a proteção ambiental, o armazenamento dos insumos e produtos, a expedição de produtos, a distribuição e o transporte, abrangendo desde o asseio pessoal dos funcionários, isolamento da fábrica, higienização de equipamentos, utensílios e instalações tudo para assegurar a qualidade do produto final (RIBEIRO, 2009).

Para que se obtenha melhor qualidade da ração, os estabelecimentos devem estar situados em zonas isentas de odores indesejáveis e contaminantes. Fora de área de riscos de inundações e alojamento de pragas. Longe de outras atividades industriais que possam prejudicar a qualidade dos alimentos para os animais, a não ser que haja medidas de controle e segurança que evitem os riscos de contaminação (MAPA, 2007).

$\mathrm{Na}$ percepção de VARGAS e RASZI (2012), a utilização das BPF em indústria de alimentos para animais é uma metodologia indiscutível que consiste em estabelecer normas que padronizem e definam procedimentos e métodos que regulamentam todas as atividades de fabricação de um produto e ou a execução de um serviço, conscientizar colaboradores para práticas adequadas de higiene e manipulação dos alimentos, reduzir a níveis aceitáveis as contaminações e garantir a segurança e qualidade dos produtos.

A razão da existência das BPF está em ser uma ferramenta para combater e minimizar as contaminações microbiológicas, físicas e químicas. Deste modo, investir em treinamentos das pessoas envolvidas nas atividades, capacitá-las a executar as regras das BPF, com proposito de obter processos claros, livres de defeitos e contaminações, que resultem em produtos e serviços seguros (ALVES, 2005).

Uma vez que os principais problemas relacionados à implantação das BPF em indústrias podem-se destacar: a falta de pessoal capacitado para este objetivo, outro obstáculo é a ausência de investimentos. Como se trata, principalmente, de um programa que exige mudanças comportamentais e disciplinares, consiste em um desafio em cada empresa para manter o êxito produtivo e qualitativo (MICHALCZYSZYN et al., 2008).

CANTO (1998) reporta que as BPF possuem três objetivos fundamentais. O primeiro é caracterizado como a unificação da linguagem dos princípios básicos de como ter e obter boas práticas de fabricação para produtos destinados à saúde humana e animal. O segundo objetivo está em comprovar que a empresa que faz uso das 
BPF já se encontram em estágio superior em qualidade de seus produtos. O terceiro é atingir a qualidade assegurada dos produtos acabados, com possibilidades de certificações ainda mais rigorosas.

Entretanto, segundo MAZZUCO (2015) o objetivo específico da utilização da BPF estende-se a garantia da rastreabilidade; conscientização sobre higiene pessoal; garantia da qualidade nutricional dos alimentos virgula evitando a contaminação física, química ou biológica; programas de erradicação de pragas; os utensílios e equipamentos que devem ser projetados de modo a assegurar a limpeza e a higiene evitando contaminações; quanto ao projeto/fluxograma de instalações e prédios; procedimento de desinfecção e limpeza de equipamentos e utensílios usados na fabricação das rações e manipulação de ingredientes; a garantia de controle dos processos, reduzindo os custos e padronizando os procedimentos. Os requisitos de BPF aplicam-se quanto à qualidade das matérias-primas (análise, registros e procedência).

SILVEIRA (2014) em experimentação em dois anos consecutivos avaliou a ocorrência de contaminação por Salmonella spp. em amostras de ambiente e rações de uma fábrica de ração para aves e identificou elevada ocorrência de contaminação por Salmonella spp. na área externa do telhado da fábrica $(55,6 \%)$ o que pode indicar falhas no processo de BPF a partir da contaminação cruzada.

A alta taxa de contaminação nesta área pode ter facilitado o transporte desse microrganismo para a área interna por meio de pragas e equipamentos (Tabela $3)$, visto que a empresa apresentou desvios no plano de ação com relação ao controle de pragas e problemas estruturais na fábrica. Outro ponto de contaminação importante são as botas dos operadores que apresentaram $20 \%$ de ocorrência de contaminação.
Tabela 3. Pesquisa da ocorrência de Salmonella spp. (\%) em amostras de equipamentos da área limpa da fábrica de ração.

\begin{tabular}{lcc}
\hline \multirow{2}{*}{ Equipamentos } & \multicolumn{2}{c}{ Anos } \\
\cline { 2 - 3 } & $\mathbf{2 0 1 3}$ & $\mathbf{2 0 1 4}$ \\
\hline Elevador e pé do elevador & 0,0 & 0,0 \\
Transportador horizontal & 0,0 & 2,6 \\
Silos de expedição & 12,2 & 18,8 \\
Triturador & 5,9 & 7,1 \\
Exaustor & $*$ & 0,0 \\
Condicionador & $*$ & 0,0 \\
Prensa & 0,7 & 1,8 \\
Resfriador & 15,4 & 11,9 \\
*Análise não realizada. & & \\
\hline
\end{tabular}

Fonte: SILVEIRA (2014).

Para RICHARDSON e LONGO (2008) a não conformidade com a implantação da BPF resulta em risco à saúde pública, devido a presença de microrganismos em rações comprometendo a biossegurança dos lotes e o desempenho dos animais, aumentando a responsabilidade dos fabricantes a fim de assegurar a qualidade prometida e consequentemente aumenta a competitividade da empresa/indústria, reduzindo as barreiras comerciais em virtude da excelência na qualidade confirmada por programas como o BPF (BELLAVER, 2001).

É necessário cada estabelecimento possuir um manual próprio de BPF, que atenda as exigências do regulamento e que contenha os seus Procedimentos Operacionais Padrão (POP), com as instruções detalhadas sobre os cronogramas, procedimentos e métodos empregados na realização de operações específicas relacionadas à produção. O manual deve ser claro e preciso e todas as operações devem ser realizadas de acordo com o mesmo (MASCARENHAS, 2012).

Procedimento operacional padrão (POP). Em uma definição bem concisa, para ANARUMA (2009) POP é entendido como a descrição pormenorizada e objetiva de instruções, técnicas e operações rotineiras a serem utilizadas pelos fabricantes de produtos destinados à alimentação animal, visando a proteção, a garantia de 
preservação da qualidade e da inocuidade das matérias-primas e produto final e a segurança dos manipuladores. Fazendo-se imprescindível a adoção do manual e uso do POP (OLIVEIRA, 2014).

É necessário que tal procedimento tenha formato padronizado e seja descrito de maneira objetiva e prática, em linguagem que possa ser entendida pelos executores do mesmo. Devem estar listados todos os materiais e equipamentos necessários para a realização da operação, a metodologia, a frequência, o monitoramento, as ações corretivas bem como os responsáveis pelas execuções. Precisam ser aprovados, datados e assinados (MAPA, 2007).

É necessário que sejam revisados no mínimo uma vez por ano, com intuito de verificar se estão atendendo ao seu objetivo, sendo ajustado sempre que se fizer necessário e devem ser alterados toda vez que houver qualquer modificação no procedimento operacional da empresa (MASCARENHAS, 2012).

Conforme a Instrução Normativa no 4 de 23 de fevereiro de 2007, devem ser implantados POP's contemplando no mínimo os seguintes itens: qualificação de fornecedores e controle de matériasprimas e de embalagens; limpeza e higienização de instalações, equipamentos e utensílios; higiene e saúde do pessoal; potabilidade da água e higienização de reservatório; prevenção de contaminação cruzada; manutenção e calibração de equipamentos e instrumentos; controle integrado de pragas; controle de resíduos e efluentes; programa de rastreabilidade e recolhimento de produtos (MAPA, 2007).

O uso do POP para qualificação de fornecedores e controle de matériasprimas e embalagens possui a finalidade de especificar os critérios utilizados e os procedimentos adotados para a qualificação e o controle dos mesmos (TUCCI, 2008).

É imprescindível o controle de qualidade dos ingredientes e matérias-primas, devendo ser realizada inspeção, classificação e, análise laboratorial dos ingredientes ainda no veículo de recebimento (Figura 1) antes da matéria-prima ser alocada dentro da fábrica. Sempre serão utilizados ingredientes e matérias-primas em boas condições na fabricação de produtos destinados a alimentação animal (MOTA, 2010).

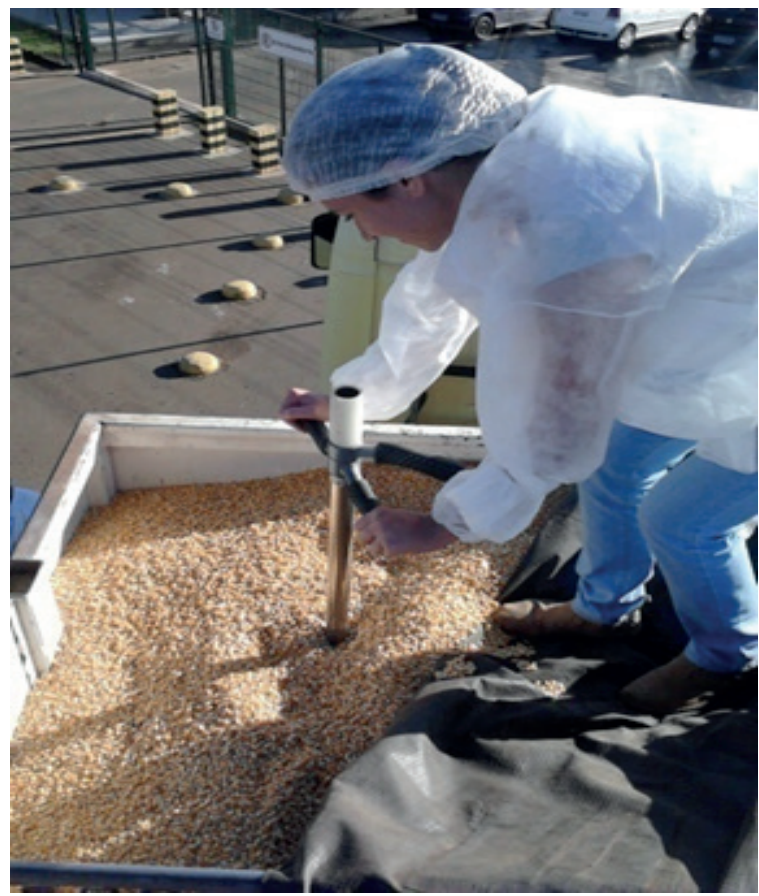

Figura 1. Coleta de amostras de milho grão utilizando calador específico para cargas a granel em fábrica de ração. Fonte: Arquivo pessoal, (2014).

Deve-se atentar no momento da recepção que, somente serão aceitas as matériasprimas que estiverem devidamente embaladas (minerais) em uma embalagem original, esta deve estar devidamente rotulada e sem avarias. As matériasprimas, que estiverem com algum tipo de contaminação física, química e/ou microbiológica que não possa ser reduzida a níveis aceitáveis antes ou durante o processo de industrialização, não serão aceitas e/ou recebidas pelas empresas (RIBEIRO, 2009).

Diariamente além da classificação de matéria-prima, uma série de atividades relacionadas aos Procedimentos Operacionais Padrões (POP) de responsabilidade do controle de qualidade são registradas e enviadas para todos os 
técnicos envolvidos no setor da fábrica de ração na forma de check list (OLIVEIRA, 2014).

Com relação ao POP para prevenção de contaminação cruzada, este deve identificar os possíveis locais e as formas de ocorrência, aplicando os princípios obrigatórios do POP. Logo, seu controle integrado de pragas na fábrica de ração necessita contemplar as medidas preventivas e de controle no estabelecimento em relação aos insetos e pequenos roedores (TUCCI, 2008).

Segundo dados do Mapa (2007) a contaminação de um produto por outro produto afetando a inocuidade deste. Este fato e ocasionado durante o processo de produção ou gerada pelo contato indevido de ingrediente, insumo, superfície, ambiente, pessoas, insetos, roedores ou produtos contaminados (Tabela 3). Ressaltando a necessidade de que as diversas matériasprimas, embalagens e produtos acabados devem ser identificados e armazenados separadamente e de acordo com suas particularidades.

O processo de fabricação dos diferentes produtos segue uma sequência de produção racional como forma de evitar a contaminação cruzada, levando-se em consideração a categoria e espécie animal a qual se destina o produto. Observa-se em sua composição a adição de antibiótiocs ou não, aditivos dentre outros compostos químicos. Levando-se em consideração a ordem de fabricação de acordo com a sensibilidade do animal a determinados ingrediente da ração. Como por exemplo as rações para equinos devem ser fabricadas antes de bovinos por serem animais mais sensíveis, a alguns ingredientes utilizados na fabricação de rações para bovinos podem ser prejudiciais a sua saúde (RIBEIRO, 2009).

Como medidas de limpeza e higienização das instalações, o POP desta modalidade deve possuir informações relacionadas às operações, produtos utilizados com a devida concentração, princípio ativo e tempo de ação (MOTA, 2010).
O colaborador que realiza esse trabalho deve ser treinado nos procedimentos instituídos. E todos os equipamentos e utensílios utilizados nos locais de manipulação de matérias-primas, que possam entrar em contato com o mesmo, devem ser feitos de materiais que não transmitam substâncias tóxicas, odores, sabores e que não sejam permeáveis, resistentes à corrosão e capazes de resistir a repetidas operações de limpeza e desinfecção (RIBEIRO, 2009).

Já o POP referente à higiene e saúde dos colaboradores trabalhadores na indústria de alimentos de ração precisa especificar, no mínimo, os procedimentos em relação ao uso e higiene dos uniformes, hábitos higiênicos, exames laboratoriais, atestados médicos, presença de funcionários com lesões visíveis ou sintomas de infecções e treinamento específico, tornando indispensável o uso do equipamento de proteção individual (EPI) na indústria, com emprego de equipamentos tais como luvas, máscaras, tampões, óculos, aventais e outros são obrigatórios, os mesmos devem estar em perfeitas condições de higiene e limpeza. No caso de luvas, o seu uso não dispensa o manipulador da obrigação de lavar as mãos cuidadosamente. O uso de máscara para boca e nariz é obrigatório em alguns setores na fábrica de ração (MAPA, 2007).

Quanto ao POP para potabilidade da água e higienização de reservatório, este precisa especificar o padrão de potabilidade microbiológico e físico-químico, incluindo todas as etapas: captação, tratamento, armazenamento, distribuição, pontos de colheita de amostras, análises, monitoramento, ações corretivas, verificação e registros. É extremamente necessário estabelecer sempre a frequência da execução das análises, monitoramentos, da verificação e da limpeza dos reservatórios (MOTA, 2010).

A utilização da água não potável é permitida quando é destinada para a produção de vapor, controle de incêndio e outros fins análogos. Toda a água utilizada para formulação, limpeza de instalações e equipamentos e higiene pessoal deve ser 
Melo et al - Legislação e ferramentas de gestão no controle de qualidade da matéria-prima

potável. A água potável é definida como aquela que está isenta de microrganismos patogênicos (ANVISA, 2006).

Em relação ao POP para o controle de resíduos e efluentes, este, estabelece os procedimentos de manejo dos resíduos, evitando contaminação cruzada, acesso de pragas e contaminação ao meio ambiente se faz necessário dentro deste (MAPA, 2007).

Com exceção dos volumes de águas usadas nos produtos e pelas perdas por evaporação, as águas tornam-se contaminadas por resíduos do processo industrial ou pelas perdas de energia térmica, originando assim os efluentes (SILVA et al., 2013). Para se obter controle eficiente de efluentes e águas residuais as indústrias processadoras de alimentação animal devem dispor de um sistema eficiente de eliminação de efluentes e de tratamento de águas residuais a fim de evitar a contaminação do abastecimento de água potável (MOTA, 2010).

As características físicas, químicas e biológicas do efluente industrial são diversificadas de acordo com o tipo de indústria, com o tempo de operação, com a matéria-prima utilizada, com a reutilização de água dentre outros. A partir disso, o efluente líquido pode ser solúvel ou com sólidos em suspensão, podendo se apresentar com ou sem coloração, orgânico ou inorgânico, com temperatura variada (baixa ou elevada). Entre as determinações mais comuns para caracterizar a massa líquida estão as determinações físicas (temperatura, cor, turbidez, sólidos etc.), as químicas ( $\mathrm{pH}$, alcalinidade, teor de matéria orgânica, metais etc.) e as biológicas (bactérias, protozoários, vírus etc.) (CIMM, 2009).

O POP para o programa de rastreabilidade e recolhimento de produtos, conhecidos como Recall, deve descrever como será a rastreabilidade, por meio do histórico de cada lote ou partida produzida, desde a origem das matérias-primas utilizada até o destino final do produto acabado, além dos responsáveis pela atividade. Cada empresa terá seu próprio controle de rastreabilidade, mas sempre seguindo os requerimentos exigidos pela In. $n^{\circ} 4$ de 2007 do MAPA (MAPA, 2007).
Este é um procedimento com a finalidade de detectar a origem dos problemas da matéria-prima e/ao longo de todas as fazes de produção, transformação e distribuição. A rastreabilidade é obrigatória para todas as empresas manipuladores de alimentos (FREITAS, 2011).

\section{Análises de perigos e pontos críticos de controle (APPCC)}

A produção de alimentos em indústrias processadoras de ração animaléconsiderada um processo complexo e durante a sua elaboração podem ter inúmeras variáveis as quais podem prejudicar a qualidade e consequentemente 0 desempenho dos animais (CORADI et al., 2009). Segundo SINDIRAÇÕES (2002), estas variáveis são denominadas ponto crítico de controle, ou seja, é a etapa do processo em que o controle deve ser aplicado para se prevenir ou eliminar um perigo ou reduzi-los a níveis aceitáveis.

Nessa ótica, o sistema de análise de perigo e pontos críticos de controle (APPCC) é um instrumento de ações preventivas para a detecção dos perigos e dos pontos críticos de controle, cujo foco é a atenção para o controle de fatores chave que afetam diretamente a segurança e a qualidade da cadeia alimentar. É um sistema elaborado para prevenir a ocorrência de problemas, assegurando que os controles são aplicados em determinadas etapas no sistema de produção de alimentos, onde possam ocorrer perigos em situações críticas. O sistema é aplicável em todas as etapas do processamento da ração, comercialização e, por fim, o uso em estabelecimentos comerciais ou diretamente pelo animal (ALVES, 2003).

De acordo com as definições do SINDIRAÇÕES (2008), é considerado como perigo qualquer aspecto da cadeia agroindustrial que seja inaceitável por ser uma causa potencial de problemas de comprometimento da conformidade e da segurança alimentar. Já ponto crítico de controle é entendido como etapa do processo em que o controle deve ser aplicado e é essencial para se prevenir ou eliminar um perigo ou reduzi-lo a um nível aceitável. 
Na sigla APPCC, o AP representa Análise de Perigos, e é considerada a peça chave para todo o sistema, especialmente para a determinação dos PCC (Pontos Críticos de Controle). Os perigos podem ser: químicos (inseticidas, desinfetantes), físicos (corpos estranhos) e biológicos (microogranismos) (RIBEIRO-FURTINI e ABREU, 2006).

Antes da implantação do sistema APPCC, dois pré-requisitos se fazem necessários, as BPF e OS POP (RIBEIRO-FURTINI e ABREU, 2006). Sendo de interesse mundial sua implantação em todas as indústrias de alimentos. E a adequada aplicação desse sistema pode identificar e avaliar as ameaças potenciais associadas com o armazenamento, fabricação e entrega de alimentos, bem como as medidas adequadas e eficazes para eliminar ou reduzir o perigo em fases específicas de produção (FONSECA et al., 2013).

Esta é uma ferramenta indispensável, devido principalmente à sua abrangência, determinando ações simultâneas e procedimentos interdependentes. A aplicação dessa ferramenta considera uma sequência lógica dos princípios e das etapas básicas da fabricação da ração (CORADI et al., 2009).

A aplicação dos princípios do APPCC é realizada, considerando-se uma sequência lógica das etapas e dos princípios básicos de fabricação da ração. Para sua elaboração é necessário um plano de ação que constitui, inicialmente, em análises de riscos dos produtos expostos no local de processamento. A análise de risco constituise de análise científica de efeitos adversos, conhecidos ou potenciais, resultantes da exposição de um indivíduo a agentes perigosos (CORADI et al., 2009).

O uso do sistema APPCC proporciona um produto de qualidade fornecido aos animais, torna as empresas mais competitivas, expande as possibilidades de conquistas de novos mercados nacionais e internacionais, além de contribuir para a redução de perdas de matérias-primas, embalagens e produtos, estabelecendo como premissa que produtos seguros serão resultados de ingredientes e processos seguros (COUTO, 2008).
A implantação do APPCC na indústria processadora de raçoes traz credibilidade, não relacionado apenas à segurança do produto, mas também pela certeza do cumprindo as exigências das fiscalizações. Contudo, a falta de capacitação técnica e os investimentos em infraestrutura são as principais dificuldades enfrentadas para a implementação essa ferramenta de gestão da qualidade do produto acabado sistema (PINZON et al., 2011).

\section{Considerações Finais}

E possível considerar que o cumprimento da legislação vigente no Brasil para fabricantes de produtos destinados a alimentação animal é irrefutável a fim de manter a qualidade no produto final fornecido aos animais.

O uso das BPF consiste em estabelecer normas que padronizem e definam procedimentos e métodos que regulamentam todas as atividades de fabricação de um produto e ou a execução de um serviço.

Já o POP tem como princípio as instruções, técnicas e operações rotineiras a serem utilizadas pelos fabricantes de produtos destinados à alimentação animal.

A APPCC é a etapa do processo em que o controle deve ser aplicado para se prevenir ou eliminar um perigo ou reduzi-los a níveis aceitáveis controlando os fatores chave que afetam diretamente a segurança e a qualidade da cadeia alimentar.

O controle de qualidade da matéria-prima é essencial a fim de assegurar a garantia da inocuidade de um produto final de confiança, que atenda às exigências do mercado e consequentemente dos animais, que se aproxime ao máximo das especificações ou padrões estabelecidos para o qual fora criado e que atenda à legislação vigente e às inspeções dos órgãos federais ligados ao setor. Fazendo-se imprescindível o uso de tais ferramentas de gestão na qualidade e segurança dos alimentos oferecidos aos animais de produção. Em que, as BPF e o POP são pré-requisitos essenciais à implantação do APPCC. 


\section{REFERÊNCIAS}

ALLTECH GLOBAL FEED SURVEY. 2017. Produção de ração mundial cresceu $19 \%$ nos últimos cinco anos. Disponível em: https://pt.alltech.com/news/news-articles/2017/02/20/ producao-de-racao-mundial-cresceu-19-nos-ultimos-cinco-anos. Acesso em: 05/01/2018.

ASSOCIAÇÃO BRASILEIRA DAS INDÚSTRIAS EXPORTADORAS DE CARNE (ABIEC). 2017. Perfil da Pecuária no Brasil - Relatório Anual 2016. São Paulo.

ALVES, N.A.; BIAGI, J.D. 2015. Utilização da ferramenta boas práticas de fabricação (BPF) na produção de alimentos para cães e gatos. Portal de Pesquisa da BVS Veterinária 19:64-69.

ANARUMA, R.J. 2009. Boas práticas de fabricação e APPCC em estabelecimento de produtos destinados à alimentação animal. 190 Congresso Brasileiro de Zootecnia. Anais... Águas de Lindóia, São Paulo.

AGÊNCIA NACIONAL DE VIGILÂNCIA SANITÁRIA (ANVISA). 2006. Higiene dos alimentos Testos Básicos. Disponível em: http://www.anvisa.gov.br/divulga/public/alimentos/ codex alimentarius.pdf. Acesso em: 15/10/2015.

BELLAVER, C. 2001. Segurança dos alimentos e controle de qualidade no uso de ingredientes para a alimentação animal. In: Conferencia Virtual de Suínos e Aves. Anais... Santa Catarina: Snpsa: Embrapa, pp. 1-10

BRASIL. 2007. Decreto No 6.296, de Dezembro de 2007. Disponível em: http://www. planalto.gov.br/ccivil_03/_Ato2007-2010/2007/Decreto/D6296.htm. Acesso em: $27 / 04 / 2014$.

BRANQUINHO, M.R.; SARMENTO, S.K.; FERREIRA, R.L. 2015. Mudanças na legislação de rotulagem de OGM: Uma necessidade em função dos avanços tecnológicos. 190 Encontro Nacional e $5^{\circ}$ Congresso Latino Americano de Analistas de Alimentos. Anais... Rio grande do Norte, Natal.

CANTO, A.P. 1998. Porque e para que foi criado o cGMP. Revista Banas 8:88-89.

CENTRO DE INFORMAÇÃO METAL MECÂNICA (CIMM). 2009. Efluentes Industriais. Disponível em: https://www.cimm.com.br/portal/material didatico/3669-efluentesindustriais\#.Wk0cntKnHIU. Acesso em: 05/01/2018.

CHAVES, J.B.P. 1994. Controle de qualidade para indústrias de alimentos. Viçosa: Imprensa Universitária, 94p.

CORADI. P.C.; MELO, E.C.; LACERDA FILHO, A.F. 2009. Análise de Perigos e Pontos Críticos de Controle (APPCC) no Processo de Fabricação da Ração. Revista Eletrônica Nutritime 6(5):1098-1102. Disponível em URL: https://www.researchgate.net/ publication/280114562/doi:10.13140/RG.2.1.1112.4323

COUTO, H.P. 2008. Fabricação de Rações e Suplementos para Animais: Gerenciamento e Tecnologias. Viçosa, MG: CPT. Aprenda Fácil, 226p. 
FREITAS, G.S.R. 2011. Avaliação do sistema de análise de perigos e pontos críticos de controle em um matadouro-frigorifico de aves. Especialização (Especialista em Produção, Tecnologia e Higiene de Produtos de Origem Animal) Universidade Federal do Rio Grande do Sul - Faculdade de Medicina Veterinária. Porto Alegre, 36p. Disponível em URL: http://hdl.handle.net/10183/40126

FONSECA, C.F.; STAMFORD, T.L.M.; ANDRADE, S.A.C.; SOUZA, E.L.; SILVA, C.G.M. 2013. Hygienic-sanitary working practices and implementation of a Hazard Analysis and Critical Control Point (HACCP) plan in lobster processing industries. Food Science and Technology 33(1):127-136. Disponível em URL: http://www.scielo.br/scielo. php?script=sci arttext\&pid $=$ S0101-20612013000100 019

INTERNATIONAL FEED INDUSTRY FEDERATION (IFIF). 2014. A indústria de alimentos mundial. 2014. Disponível em: http://www.ifif.org/pages/t/The+global +feed+industry. Acesso em: 27/04/2014.

LONGO, F.A. SILVA, I.F.; LANZARIN, M.A. 2010. A importância do controle microbiológico em rações para aves. In: XI Simpósio Brasil Sul de Avicultura e II Brasil Sul Poultry Fair, Chapecó. Anais do XI Simpósio Brasil Sul de Avicultura e II Brasil Sul Poultry Fair. Concórdia: Embrapa, pp. 36-63.

MINISTÉRIO DA AGRICULTURA, PECUÁRIA E ABASTECIMENTO (MAPA). 2007. Instrução Normativa No. 4 de 23 de fevereiro de 2007. Disponível em: http://extranet. agricultura.gov.br/sislegisconsulta/consultarLegislacao.do?operacao=visualizar\& $\mathrm{id}=17664$. Acesso em: 22/04/2014.

MINISTÉRIO DA AGRICULTURA, PECUÁRIA E ABASTECIMENTO (MAPA). 2014. Alimentação Animal. Disponível em: http://www.agricultura.gov.br/animal/alimentacao. Acesso em: 27/04/2014.

MASCARENHAS, A.G. 2012. Boas Práticas de Fabricação - IN 04 de fevereiro de 2007. In: UFG. II Simpósio Sobre Métodos e Procedimentos na Fabricação de Rações e Suplementos, Universidade Federal de Goiás, Goiânia.

MAZZUCO H. 2015. Boas práticas de fabricação. Disponível em:

http://www.agencia.cnptia.embrapa.br/gestor/frango_de_corte/arvore/ CONT000fzh98d9402wx5ok0cpoo6a71axge2.html. Acesso em: 29/03/2015.

MICHALCZYSZYN, M.; GIROTO, J.M.; BORTOLOZO, E.Q. 2008. Avaliação e certificação em Boas Práticas de Fabricação de uma empresa de alimentos orgânicos no município de Ponta Grossa, PR - estudo de caso. Revista Higiene Alimentar 22(159):33-35.

MORAES, M.P. 1997. Fabricação de rações: qualidade de matérias-primas. Boletim Técnico - Amicil /AS. Goiânia, 10p.

MOTA, E.G. 2010. Indústria de Rações: Legislação e Sistema de APPCC Aplicado à Indústria de Alimentos Para Bovinos. In: VII Simcorte, Simpósio Internacional de Produção de Gado de Corte pp.112-151.

OLIVEIRA, M.D.R.; PASSOS, F.J.V.; ANDRADE, N.J. 2012. Diretriz para estudo da Higiene dos Alimentos: Ensino e Aprendizagem Baseada em Problemas/Projetos. Viçosa. 
Melo et al - Legislação e ferramentas de gestão no controle de qualidade da matéria-prima

OLIVEIRA, F. 2014. Controle de qualidade em fábrica de ração para frangos de corte. (Trabalho de Conclusão de Curso) Universidade Federal de Santa Catarina. Florianópolis - SC. 49p. Disponível em URL: https://repositorio.ufsc.br/bitstream/ handle/123456789/124629/FERNANDO\%20DE\%200LIVEIRA.pdf?sequence $=1$

PINZON, P.W.; FISCHER, P.; NOSKOSKI, L. 2011. Análise de perigos e pontos críticos de controle (APPCC). $16^{\circ}$ Seminário Inter institucional de Ensino, Pesquisa e Extensão. Anais... UNICRUZ, Cruz Alta.

REZENDE, A.C. 2003. Análise de perigos e pontos críticos de controle (APPCC) em unidades armazenadoras de grãos a granel de Campinas. Dissertação (Mestrado em Engenharia Agrícola) Universidade Estadual de Campinas Faculdade de Engenharia Agrícola. Campinas, SP, 52p. Disponível em URL: http://repositorio.unicamp.br/jspui/handle/ REPOSIP/257568

RIBEIRO, K.O. 2009. Manual de Boas Práticas de Fabricação (BPF) para estabelecimento fabricante de produtos destinados à alimentação animal. Trabalho de Conclusão de Curso (Curso de Higiene e Inspeção de Produtos de Origem Animal) Universidade Federal de Minas Gerais. Belo Horizonte. 169p. Disponível em URL: https://zootecnia. jatai.ufg.br/up/186/o/BOAS PR\%C3\% 81TICAS DE FABRICA\%C3\%87\%C3\%830 DE RA\%C3\%87\%C3\%830.pdf

RIBEIRO-FURTINI, L.L.; ABREU, L.R. 2006. Utilização de APPCC na Indústria de Alimentos. Ciência e Agrotecnologia 30(2):358-363. Disponível em URL: http://www.scielo.br/ scielo.php?pid=S1413-70542006000200025\&script $=$ sci

abstract\&tlng $=p t$

RICHARDSON, K.E.; LONGO, F.A. 2008. A importância do controle microbiológico na cadeia de produção de rações para aves. $5^{\circ}$ Simpósio sobre Manejo e Nutrição de Aves e Suínos. Anais... CBNA. Cascavel - PR; pp. 149-160.

ROSÁRIO, M.B. 2004. Controle estatístico de processo: um estudo de caso em uma empresa da área de eletrodomésticos. (Dissertação). Universidade Federal do Rio Grande do Sul, Porto Alegre, 112p. Disponível em URL: http://hdl.handle.net/10183/5663

SILVA, E.S.; LISBOA, F.D.; WERLANG, L.M. 2013. Caracterização e acompanhamento da qualidade do efluente em indústrias de bebidas: um estudo de caso. $20^{\circ}$ Simpósio Brasileiro de Recursos Hídricos. Anais... Porto Alegre - RS.

SILVEIRA, N.S. 2014. Estudo De Caso: Ocorrência de contaminação por Salmonella spp. em uma fábrica de ração de aves. Trabalho de Conclusão de Curso (Graduação em Zootecnia). Universidade Federal de Santa Catarina. Florianópolis - SC. 41p. Disponível em URL: https://repositorio.ufsc.br/xmlui/handle/123456789/133252

SINDICATO NACIONAL DA INDÚSTRIA DE RAÇÃO ANIMAL (SINDIRAÇÕES). 2008. Manual Feed \& Food Safety. Gestão do Alimento Seguro. Versão 4.0 Disponível em: http:// sindiracoes.org.br/wpcontent/uploads/2012/03/manual pffsgas versao4 0.pdf. Acesso em: 22/03/2014.

SORIA, M.C.; SORIA, M.A.; BUENO, D.J.; TERZOLO, H.R. 2013. Comparison of 3 culture methods and PCR assays for Salmonella gallinarum and Salmonella pullorum detection in poultry feed. The Journal of Applied Poultry Research 96(6):1505-1515. Disponível em URL: https://www.ncbi.nlm.nih.gov/pubmed/23687146 
TORRES, G.J.; PIQUER, F.J.; ALGARRA, L.; FRUTOS, C.; SOBRINO, O.J. 2011. The prevalence of Salmonella enterica in Spanish feed mills and potential feed-related risk factors for contamination. Preventive Veterinary Medicine 1(98): 81-87. Disponível em URL: https://www.ncbi.nlm.nih.gov/pubmed/21145122

TUCCI, F.M. 2008. Legislação Sobre Boas Práticas de Fabricação de Alimentos Para Animais In: IX Simpósio Brasil Sul de Avicultura. 2008, Chapecó, SC - Brasil. pp. 47-71.

VARGAS, E.O.; RASZI, S.M. 2012. Impacto da implementação das boas práticas de fabricação em indústria de alimentos para animais. E-Tech, Florianópolis, n. esp. Alimentos, pp. 48-68.

WEDEKIN, I.; PINAZZA, L.A.; LEMOS, F.K. 2017. Economia da pecuária de corte: fundamentos e ciclo de preços. 1.ed. Ivan Wedekin, São Paulo: Wedekin Consultores, $180 p$. 